Gut, 1973, 14, 939-942

\title{
Serum alpha-fetoprotein levels in acute viral hepatitis
}

\author{
M. C. KEW, L. R. PURVES, AND I. BERSOHN \\ From the Department of Medicine, University of the Witwatersrand and Johannesburg Hospital, School of \\ Pathology of the South African Institute for Medical Research and University of the Witwatersrand, \\ Johannesburg, and Division of Life Sciences, Atomic Energy Board, Pretoria, South Africa
}

SUMMARY Serum alpha-fetoprotein levels were measured serially by radioimmunoassay in 32 patients with acute viral hepatitis. With one exception, the levels were increased during the course of the illness. Raised concentrations of the protein occurred almost equally in patients with and without the hepatitis-B antigen. In the majority of patients the rise was modest but in seven levels were reached at which alpha-fetoprotein could be detected by immunodiffusion. Very high levels were more likely to occur in children. In eight patients the concentration increased as the serum glutamic pyruvic transaminase (SGPT) level, used as an index of hepatocyte damage, was returning to normal, a pattern which favoured increased synthesis of the protein during hepatocellular regeneration. In the remainder, the alpha-fetoprotein level paralleled that of SGPT, suggesting rather an acutephase reaction to liver injury.

Alpha-fetoprotein, an alpha ${ }_{1}$ globulin, is present in high concentration in fetal serum but in only very small amounts in the serum of children and adults (Ruoslahti and Seppälä, 1972a; Purves, Branch, Geddes, Manso, and Portugal, 1973). It has been shown to be increased in the serum of most patients with primary cancer of the liver and some patients with germinal cell tumours of the testis or ovary or tumours of entodermal origin (Abelev, 1971). Increased synthesis of the protein in these conditions is thought to be due to dedifferentiation of the neoplastic cells with derepression of the alpha-fetoprotein genome (Abelev, 1971). A transient rise in the concentration of alpha-fetoprotein in the serum of patients with acute viral hepatitis has also been reported (Abelev, 1971; Smith, 1971; Akeyama, Koyama, and Kamada, 1972; Purves et al, 1973a; Ishii, 1973; Ruoslahti and Seppälä, 1972b). The cause is not known, but possible mechanisms include liver cell retrodifferentiation during hepatocyte regeneration, viral derepression of the genome controlling alpha-fetoprotein synthesis, or an acute-phase reaction to liver injury (Werner, 1969). If the first possibility were correct, it might be anticipated that alpha-fetoprotein levels would rise as tests of liver function and damage improved,

Received for publication 28 August 1973. but if either of the other two mechanisms were operative, concentrations would be expected to follow the pattern of these tests. Alpha-fetoprotein levels and selected tests of liver cell function and integrity have been measured serially in patients with acute viral hepatitis in order to establish any correlations. Since the half-time of alpha-fetoprotein is between one and two days (Purves and Purves, 1972), serum levels reflect fairly recent events and they can be compared with serum enzyme changes in a meaningful way.

\section{Patients Studied and Methods}

Thirty-two patients with acute viral hepatitis were studied. The diagnosis was made on clinical and biochemical features and, in the case of virus-B hepatitis, by finding hepatitis-B antigen (HBAg) in the patients' serum. With four exceptions, the patients were Negroes. There were 17 males and 15 females; their ages ranged from 4 months to 43 years. They were treated with bed rest alone except for three patients who ran a fulminating course terminating in hepatic coma and who received corticosteroids and, in one case, underwent exchange transfusion. Two of the latter patients died; the remainder made a complete clinical and biochemical recovery. 
Starting on the day of or after admission, blood was taken serially during the course of the illness for liver function tests and measurement of alphafetoprotein levels. The latter were measured by radioimmunoassay (Purves and Purves, 1972). The range in normal adults in our laboratory is 1-30 ng/ml (Purves and Purves, 1972). The serum glutamic pyruvic transaminase (SGPT) was taken as the most sensitive index of hepatocyte damage, and alpha-fetoprotein levels were related to this enzyme. The patients' serum was examined for HBAg using counterimmunoelectrophoresis (Gocke and Howe, 1970) and complement fixation (Purcell, Holland, Walsh, Wong, Morrow, and Chanock, 1969).

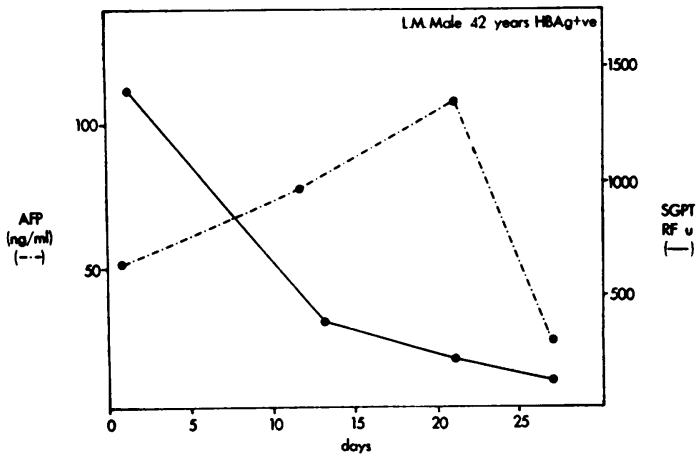

Fig 1

Figs 1 and 2 Examples of the pattern in which the serum alpha-fetoprotein concentration increased as the SGPT level was returning to normal.

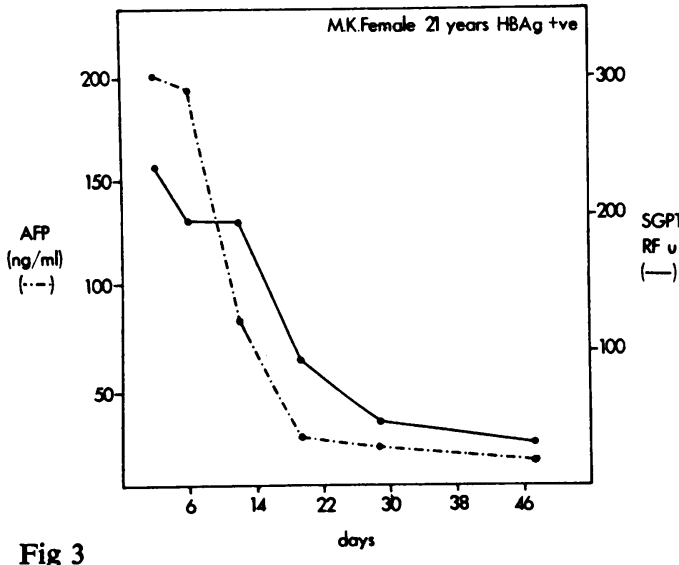

Fig 3

Fig 4 paralleled that of SGPT.

\section{Results}

In 31 of the 32 patients the serum alpha-fetoprotein concentration rose during the course of the disease. In seven the maximum level attained was greater than $1000 \mathrm{ng} / \mathrm{ml}$, the level at which the protein could be detected by immunodiffusion. The highest level recorded was $6000 \mathrm{ng} / \mathrm{ml}$. Maximum concentrations of between 500 and $1000 \mathrm{ng} / \mathrm{ml}$ were present in two patients, between 100 and 500 in 16, and less than 100 in six. One of the two patients who ran a fulminating course and died in hepatic coma had normal levels of alpha-fetoprotein $(20 \mathrm{ng} / \mathrm{ml})$ on two occasions. The other had a concentration of $1700 \mathrm{ng} / \mathrm{ml}$ on one occasion four days before she died. The third patient in whom hepatic coma supervened had a level of $340 \mathrm{ng} / \mathrm{ml}$. She recovered completely.
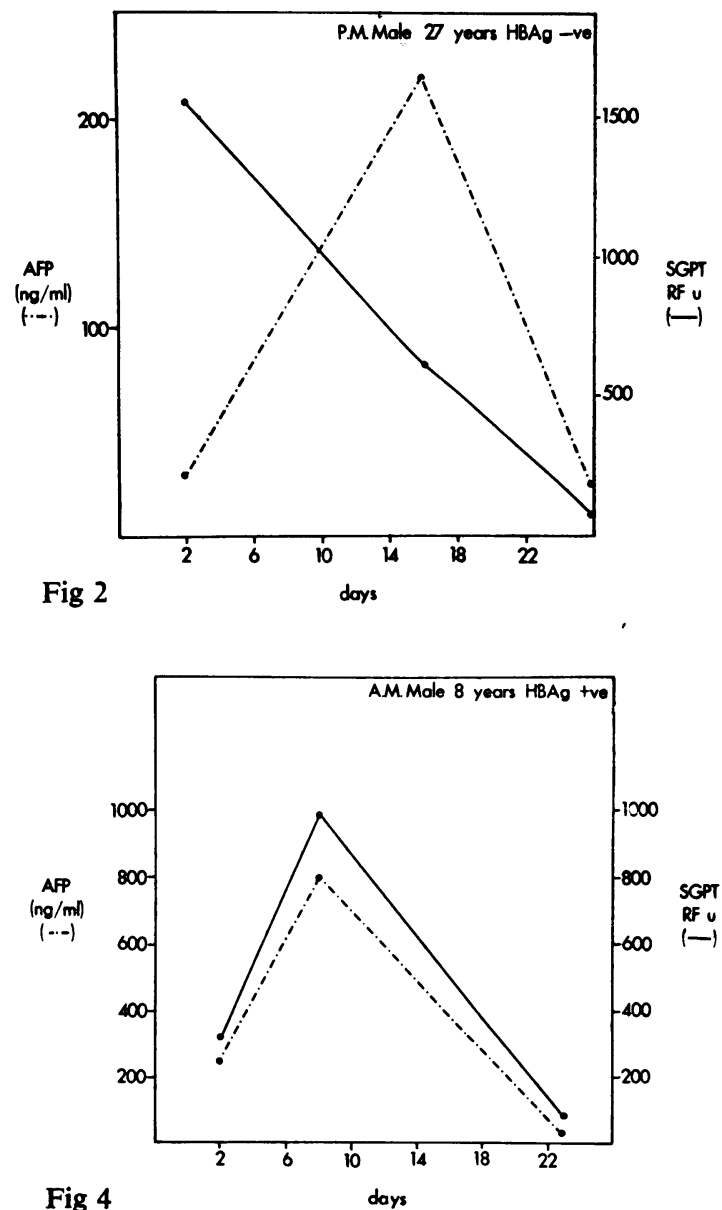
In eight patients the alpha-fetoprotein concentration increased as the SGPT level returned to normal (examples are shown in figs 1 and 2): in the remaining patients the level paralleled that of SGPT (examples are shown in figs 3 and 4). There was no obvious correlation between the degree of elevation of alpha-fetoprotein and the severity of the hepatitis or the maximal height of SGPT. There was, however, some relationship between the maximal concentration of alpha-fetoprotein and the age of the patients in that six of the seven patients with very high levels were under the age of 12 years; the exception was 29 years old. HBAg was found in the serum of 19 of the patients.

\section{Discussion}

Using a very sensitive method in 32 patients, we have shown that the serum alpha-fetoprotein level is almost invariably elevated during the course of acute viral hepatitis. However, in only a minority of patients is the increase sufficiently marked for the protein to be detected by immunodiffusion. This would explain why this phenomenon has only rarely been noted when insensitive techniques for detecting alpha-fetoprotein were used (Smith, 1971). Very high levels are more likely to occur in children, an observation which is in keeping with the experimental finding that production of alpha-fetoprotein following toxic injury to liver cells is more easily elicited in young animals (Abelev, 1971). While it should not under normal circumstances be difficult to distinguish between primary liver cancer or germinal cell tumours of the testis or ovary and viral hepatitis, the distinction may not always be easy in young children.

An increase in serum alpha-fetoprotein levels as a result of toxic, radiation, or infective hepatitis should be borne in mind when interpreting changes in concentrations in patients receiving treatment for those malignant diseases which are associated with raised levels of the protein (Purves et al, 1973a).

Smith (1971) found raised alpha-fetoprotein concentrations only in patients with virus-B hepatitis (identified by finding HBAg in the serum). In the present study, levels were shown to be elevated almost equally in patients with and without antigenaemia, confirming the experience of Akeyama et al (1972) in a smaller series. Indeed, there seems to be no good reason why alpha-fetoprotein synthesis should increase in one form of acute viral hepatitis and not the other. Persistence of HBAg after an attack of acute hepatitis has recently been incriminated in the aetiology of primary liver cancer (Vogel, Anthony, Mody, and Barker, 1970), and it has been postulated that the presence of raised alpha- fetoprotein levels allows the antigen to persist (Ziegenfuss, 1973). In the present investigation, the serum alpha-fetoprotein concentrations returned to normal after recovery from the attack of hepatitis. Moreover, we have been unable to demonstrate any correlation between the presence of alphafetoprotein (on immunodiffusion) and hepatitis-B antigenaemia in Southern African Negroes with primary liver cancer (Kew, Geddes, MacNab, and Bersohn, 1973). The link between raised levels of alpha-fetoprotein in normal people from areas with a high incidence of primary liver cancer, hepatitis, and primary liver cancer is uncertain at present (Purves et al, 197.3a; Purves, Manso, and Torres, 1973b).

We believe that normal serum levels of alphafetoprotein reflect the normal rate of liver cell turnover. Studies in which the liver of experimental animals was subjected to partial resection or toxic injury have suggested that increased production of alpha-fetoprotein occurs during regeneration of hepatocytes (Abelev, Perova, Khramkova, Postinkova, and Irlin, 1963; Abelev, 1971; Purves, 1972; Purves, 1973). The finding of Akeyama and coworkers (1972) and Ruoslahti and Seppälä (1972b) that maximal levels of alpha-fetoprotein in their patients with acute hepatitis occurred during the recovery phase of the illness favours a similar conclusion. Increased synthesis may be due to retrodifferentiation of mature liver cells during regeneration or, as suggested by the latter authors, proliferation or activation of relatively undifferentiated adult hepatocytes that have the alpha-fetoprotein genome in an unrepressed state. In the present study eight patients showed an increase in alpha-fetoprotein concentration as the SGPT level, used as an index of hepatocyte damage, was returning to normal, a pattern which would fit an hypothesis of increased synthesis during hepatocellular regeneration. In the remaining patients alpha-fetoprotein paralleled SGPT, suggesting rather an acute-phase reaction to liver injury or perhaps a direct consequence of the presence of the virus. This latter pattern was also found by Ishii (1973) in five patients with acute hepatitis.

Fulminant hepatitis with coma was present in the only patient with normal serum levels of alphafetoprotein. An acute-phase response might not be anticipated with massive liver necrosis, and the failure of the serum alpha-fetoprotein concentration to rise in such a patient might possibly be used as an index of irreversibility of the liver damage. However, in another such patient a very high level of alphafetoprotein was present.

More evidence will have to be obtained before it will be possible to decide whether the alpha-feto- 
protein response in acute hepatitis is the result of an acute-phase protein response associated with hepatocyte damage, or reflects the liver cell turnover rate and synchronous synthesis of alpha-fetoprotein as the liver recovers by regeneration.

The authors are indebted to the Atomic Energy Board for financial support and to its Director for permission to publish. Thanks are also due to the Director of the South African Institute for Medical Research for facilities granted and to Dr G. B. Miller for allowing us to study patients under his care.

\section{References}

Abelev, G. I. (1971). Alpha-fetoprotein in ontogenesis and its association with malignant tumours. Advanc. Cancer Res., 14, 295-358.

Abelev, G. I., Perova, S. D., Khramkova, N. I., Postinkova, Z. A. and Irlin, J. S. (1963). Production of embryonal alpha-globulin by transplantable mouse hepatomas. Transplantation, 1, 174-180.

Akeyama, T., Koyama, T., and Kamada, T. (1972). Alpha-fetoprotein in acute viral hepatitis. New Engl. J. Med., 287, 989.

Gocke, D. J., and Howe, C. (1970). Rapid detection of Australiaantigen by counter immunoelectrophoresis. J. Immunol., 104, $1031-1034$.

Ishii, M. (1973). Radioimmunoassay of alpha-fetoprotein. Gann Monogr. Cancer Res., 14, 89-98.
Kew, M. C., Geddes, E. W., Macnab, G. M., and Bersohn, I. (1973). In preparation.

Purcell, R. H., Holland, P. V., Walsh, J. H., Wong, D. C., Morrow, A. G., and Chanock, R. M. (1969). A complement-fixation test for measuring Australia antigen and antibody. J. infect. Dis., 120, 383-386.

Purves, L. R. (1972). Serum alpha-feto-protein. VIII. Serum levels during diethylnotrosamine poisoning of baboons. Int. J. Cancer, 10, 552-556.

Purves, L. R. (1973). Unpublished data.

Purves, L. R., Branch, W. R., Geddes, E. W., Manso, C., and Portugal, M. (1973). Serum alpha-fetoprotein. VII. The range of apparent serum values in normal people, pregnant women, and primary liver cancer high risk populations. Cancer (Philad.), 31, 578-587.

Purves, L. R., Manso, C., and Torres, F. O. (1973). Serum alphafeto-protein levels in people susceptible to primary liver cancer in Southern Africa. Gann Monogr. Cancer Res., 14, 51-66.

Purves, L. R., and Purves, M. (1972). Serum alpha-feto-protein. VI. The radio-immunoassay: evidence for the presence of AFP in the serum of normal people and during pregnancy. $S$. Afr. med. J., 46, 1290-1297.

Ruoslahti, E., and Seppälä, M. (1972a). Alpha-fetoprotein in normal serum. Nature (Lond.), 235, 161-162.

Ruoslahti, E., and Seppälä, M. (1972b). Normal and increased alphafetoprotein in neoplastic and non-neoplastic liver disease. Lancet, 2, 278-279.

Smith, J. B. (1971). Occurrence of alpha-fetoprotein in acute viral hepatitis. Int. J. Cancer, 8, 421-424.

Vogel, C. L., Anthony, P. P., Mody, N., and Barker, L. F. (1970). Hepatitis-associated antigen in Ugandan patients with hepatocellular carcinoma. Lancet, 2, 621-624.

Werner, M. (1969). Serum protein changes during the acute phase reaction. Clin. chim. Acta, 25, 299-305.

Ziegenfuss, J. F. (1973). Immunotherapy for Australia-antigen associated hepatoma. Lancet, 1, 1365-1366. 